\title{
Reflection on the Project of Hazel Forest Tourism EcoPark in Yitong County Under the Background of Internet Plus
}

\author{
Hui Yang \\ Tourism College of Changchun University , No.6543, Weixing Road, Changchun, China, 130022
}

Keywords: Internet Plus, Hazel Forest, Tourism Exploiting

\begin{abstract}
Relying on the features of the Northeast Forestry Economy and adapting the Internet technology, a Project of Hazel Forest Tourism EcoPark is initiated in Yitong County Under the Background of Internet Plus. It will provide a breakthrough impetus for the development of forestry real economy in the central area of Jilin Province. In this paper, core concepts of Internet Plus, Hazel Forest Resources of Yitong County, the project of Hazel Forest Tourism EcoPark, are expounded; analyses on the significance of the exploiting of Hazel Forest Tourism EcoPark are conducted. The feasibilities of the exploiting are discussed from the perspectives of location, administrative environment and market ;several suggestions are proposed based on the background of Internet Plus.
\end{abstract}

\section{Introduction}

In the Northeast, under the condition of comprehensive limit lumbering, the industry structure of forestry is changed, and the reforms of forestry focus on sustainable development, reconverting the farmland into forest and developing agriculture and forestry economy. With the thriving of Internet Plus, it will provide impetus for the forestry real economy in the central areas of Jilin Province by applying new ideas and technologies, relying on the features of the Northeast Forestry Economy, adapting the Internet technology, setting up a Project of hazel forest Tourism EcoPark is initiated in Yitong County Under the Background of Internet Plus.

\section{Core Concepts}

\section{Internet Plus.}

On July 4th,2015, China's State Council issued the Guidance on actively promote the "Internet plus" action. It's the first time that the phrase "Internet Plus" appeared in the Prime Minister's government work report, and that represents a new social economic pattern, i.e., Internet deeply integrating with traditional industries.

Internet Plus integrating with forestry and tourism is a new idea which may contribute a new growth point in traditional forestry and tourism industries.

\section{Hazel Forest Resources of Yitong County.}

Affiliated to to Siping,Jilin Province, Yitong Manchu Autonomous County, short for Yitong County, is in the central region of Jilin Province rich in forestry resources and belongs to an area of temperate coniferous and broad leaved mixed forest. Hazel is a sort of important dry fruit trees species,which are massively planted and expanded in the economic forest planting base established 
in Yitong County under the grand background of reconverting the farmland into forest and developing agriculture and forestry economy in recent years.

\section{The Hazel Forest Tourism EcoPark Project.}

On the basis of the advantages in geography and location, the local government proposed a strategic concept of building the back yard garden of Changchun City for tourism and leisure. The research contents of this subject are aimed at carrying out the strategy of Yitong tourism development, setting up novel projects of new Pleasure-in-farmhouse and planning the artificial hazel forest, which planted by Desheng Agriculture and Animal Husbandry Science and Technology Development Co., Ltd., into a Tourist Attraction hazel forest tourism EcoPark Project, underpinned by the idea of constructing the back yard garden.

\section{The Significance of the Project}

Yitong, as an autonomous county with rich folk culture, owns tourism resources like Dagu Mountain Scenic Area, Nanshan tourist scenic spot, Shoushan Lake, Manchu Museum and Pastoral Valley Tourism Scenic Spot and so on. Generally, the development of Yitong's tourism is concertrated on the scenic regions. Nevertheless, as an underdeveloped minority region, Yitong is not renowned as a paradise for tourists and attracts only a small amount of tourist.

The conventional hazel forestry industry, to which the hazels contributed the only profit source of primary industry, is inadequate in commercial value. Convert the artificial hazel forest in Jingtai Town into a tourism EcoPark is, in ecological function aspects, beneficial for soil and water conservation and ecological effects,and in society aspects, is conducive to raise the revenue and social awareness of Yitong.

\section{Feasibility}

\section{Location Advantage.}

Yitong County, adjacent to Changchun,the capital city of Jilin Province and 25-minute drive to the urban, is with great location advantages. At the same time, it's a crucial component of the Changchun Half-hour economy Circle and a necessary joint that links the 4 districts and 16 cities (or counties) together, which is convenient in traffic to develop tourism projects.

\section{Administrative Environment.}

The county government of Yitong are endeavoring to expand the E-Commerce in Yitong Pattern thus to transform and upgrade the traditional economy which established a benign administrative environment for the implementation of the proposed project. Considered the condition of the present rural area's E-Commerce, the local government put forward the strategy of 'Gain breakthroughs by establishing a model county of E-Commerce in rural areas' and aimed at giving impetuses to the Green transformation and upgrade in county area economy through informatization methods. The reality of the region underlying, new patterns of Yitong E-Commerce's development can be created. The main characters of Yitong pattern is featured by establishing the On-palm E-Commerce platform and the Three Rural Comprehensive Information Service platform, and by marking "Internet plus circulation, banking, Three Rural, enterprise start-up and service”.

\section{Market Analysis.}

Although hazel is a well-known typical specialty of the Northeast in Jilin Province and attracts numerous visitors to purchase, however, in present time, similar tourism projects that center on the hazel forest have not come into being. In the current market that with no competitors, the proposed project is designed to take the lead in offering an origin place of hazels as the resources of tourism 
which is full of creativity.

\section{Several Suggestions Based on the Background of Internet Plus.}

\section{Tourism industry needs a good establish of official website in the backdrop of Internet Plus.}

Conducting the marketing of tourism resources is the fundamental content. Currently, the main force of the rural area tourism is those under 45 years of age and on high incomes in urbans, who are the target group using Internet extensively. Meanwhile, as an information intensive industry, the tourism requires a good establishment for the official website. At present, quite a number of tourism resources lacks official websites or operates in poor states with no appropriate maintenance, which exposes significant issues and weakness in tourism in the backdrop of Internet Plus.

In order to improve the persuasion and influence of official websites, Tourism related departments of Yitong County Government are advised to take charge to establish and maintain the local tourism official website. In the official website, the Jing Tai town Hazel Forest EcoPark's information, such as the position, transportation, tourism project content, price, and scenery, scenic video, accommodation conditions, event notification, open time, and booking shuttle information should be exhibited onto the website; Message consulting, online communication and other functions alike need to be designed for the tourists' Tourism information service requirements. Meanwhile, for foreign visitors, multilingual services can be provided.

\section{Non-mainstream Network Marketing Channels.}

In non-mainstream network marketing channels, the computers, smart phones and tablet PCs need to be integrated into Internet. The main approach: to establish Yitong County Hazel Forest EcoPark tourism's propaganda position in the network,and to use the Internet for tourists to provide tourists with information consultation, hazel commodity sales on E-Commerce and similar functions and services. Particularly, young people frequently use software like Mafengwo Free Tour, Lvmama travel, tuniu and Ali, etc. Additionally, WeChat public accounts' tourism information promotion is also non-mainstream media publicity that suitable for young people.

The tourism industry under the Internet Plus background needs to offer good services for self-driving tour.

Self-driving tour as a new form of tourism has been favored increasingly by vast number of young tourists. Therefore, the tourism industry under the Internet Plus background asks for self-driving tour services. Firstly, the road goes straight in to Hazel Forest EcoPark should be built with adequate parking spaces. Services like travel route navigation, Online booking and vehicle driving should be improved in order to further meet the needs of self-driving tours.

\section{Establishing and improving the organization.}

At present, some local governments have already established organizations like Hazel Industry Associations, relying on leading enterprises to put the farmers in motion, to scale up industrial, and set up research institutes to breed hazel varieties energetically, and establish then processing enterprises of hazel products to do secondary processing and sale. Besides, some governments created 'Hazel Picking Day' to attract foreign merchants and consumers. Based on the above approaches of other local governments, research group think we can also take the following ways in allusion to the project of Hazel Forest Ecopark tourism under the background of Internet Plus: enterprise operation mode depending on E-commerce, implementing agricultural futures, carrying out the orders service of the hazel products, promoting tourism information promotion like Hazel Forest Ecopark Tourism、 hazel picking day, and online consultation, improving traceability system construction of hazel products, setting up video surveillance system in the management framework 
of associations and enterprises to monitor the production and processing process real time, realizing overall management of the two-dimensional code traceable of export products.

\section{Riching tourism products of the Hazel Forest EcoPark.}

We can design a tourism product system including a variety of activities, such as campfire, picking, fishing, hunting, planting, featured sales, outdoor adventure, catering entertainment, Manchu nationality amorous show, camping, hazel forest exhibition, hazel forest photo exhibition and so on. For each tourism product, we improve information management by feedback form via the internet. That is to say, through setting the network opinion feedback function and network evaluation function, we can know the service quality and tourists' advice of the Hazel Forest Ecopark Tourism project of Jingtai town, forming the tourism quality management system of the hazel forest ecological park of Jingtai town based on P-D-C-A work cycle management concept and internet.

\section{Establishing Intelligent Travel System.}

To set 2D code identification in Hazel Forest EcoPark, and covered the EcoPark with free wireless network. Based on the live-action, special events and services of the Hazel Forest EcoPark, we can realize 3D virtual tour of the hazel forest with vrp-travel virtual tour platform technology, and we can also prepare corresponding commentary to let tourists experience tourism on the internet in advance

\section{Conclusion}

Yitong County, which is close to provincial capital, is a nature travel habitat with beautiful natural environment, rich resources of animals and folk culture, the artificial hazel economic forest of Yitong County can be exploited as a forest attraction for its good ornamental value. If the artificial hazel economic forest of Jingtai Town can be a new attraction, travel resources of Liaoning Province will be rich, tourism development strategy of Yitong County will be implemented, the new pleasure-in-farmhouse tourism project of Yitong County will be started, and the development of local tourism will be promoted.

\section{Acknowledgements}

This paper is supported by Social Scientific Research Fundation "The 13th Five-year Plan" of the Education Department of Jilin Province, China (2016-560)

\section{References:}

1. B.Z.Guan and S.Lu. Domestic Agricultural and Tourism Review[J], Anhui Agricultural Science Bulletin, 2006(13).(In Chinese)

2. X.L.Zhang. Analysis of the Development of Agricultural Ecological Tourism[J], Anhui Agricultural Science Bulletin(the semimonthly), 2010(11). (In Chinese)

3. M.Yang and J.Y.Li. Study on the Exploitation of High and New Agricultural Tourism-Taking National Agricultural High and New technology Industries Demonstration Zone for example[J], Anhui Agricultural Science, 2003(4). (In Chinese)

4. N.Yang, X.M.Li and Y.Q.Fan. Problems and Countermeasures of the Development of Agricultural Ecological Tourism in Shanxi[J], Anhui Agricultural Science, 2007(25). (In Chinese)

5. L.Peng and S.L.Wei. First Study on the Exploration of Agricultural Tourism Products[J], Anhui Agricultural Science, 2007(28). (In Chinese) 